\title{
Global forestry and land use change dynamics in intertemporal general equilibrium
}

\author{
$\underline{\text { J.A. Lennox }}^{a}$, J.A.Turner ${ }^{b}$, A. Daigneault ${ }^{a}$ and K. Jhunjhnuwala ${ }^{a}$ \\ ${ }^{a}$ Landcare Research, Lincoln and Auckland, New Zealand \\ ${ }^{b}$ AgResearch Ltd., Hamilton, New Zealand \\ Email: lennoxj@landcareresearch.co.nz
}

\begin{abstract}
Management of forests for timber and other values, deforestation and afforestation are subjects of major policy interest, with important implications for climate change and food security inter alia. To robustly quantify impacts of policies on forests and on land use generally requires accounting for economic interactions not only between agricultural and forestry, but also energy and other sectors. At larger scales, these interactions may include linkages via international trade. General equilibrium models are well suited to capture such interactions; however, adequate representation of land use change and forestry in these models remains challenging.
\end{abstract}

We present a dynamic bottom-up representation of forestry within a top-down intertemporal general equilibrium model that is formulated as a mixed complementarity problem (Mathiesen, 1985; Lau et al., 2002). Intertemporally optimal management of forests and optimal harvest ages are determined endogenously within the model, bringing into an intertemporal general equilibrium farmework features hitherto limited to partial equilibrium models (e.g. the Global Timber Model Sedjo and Lyon, 1990; Sohngen et al., 1999) or recursive dynamic general equilibrium models (Pant, H.M. 2010).

Planted or naturally regenerating production forests are represented by a set of multiperiod production functions corresponding to a discrete set of harvest ages. Complementarity between negative profits and output allow for the endogenous selection of the optimal age(s) at any time under conditions of perfect foresight. A comparable bottom-up treatment of timber production from and clearance of primary forests is the subject of ongoing research. These dynamic representations of forestry in a general equilibrium framework will allow for more robust assessments of policies such as domestic greenhouse gas emissions trading schemes or Reducing Emissions from Degradation and Deforestation (REDD) Plus in developed and developing countries.

Computational limitations on direct bottom-up integration may be prohibited for models with more sectoral or regional detail. However, larger models should be tractable with the aid of decomposition techniques, which allow for tight and theoretically consistent linking of a top-down general equilibrium model with bottom-up partial equilibrium sub-models. This is also the subject of our own-going research

An illustrative scenario using a four-region version of our CliMAT-DGE model with bottom-up forestry showed the effects of carbon credits for HWPs in the US, within a wider context of $\mathrm{CO}_{2}$ emissions pricing by developed countries. We showed not only a significant expansion of forestland and output in the US, but changes in age composition of the forest estate and harvest ages during a six decade transition. Marginal flow-on effects of the US HWP credits were small, but larger effects could be expected for policies affecting a larger share of global forest production, or in regions where forestry is economically more important.

Computational considerations limit the number of regions and the level of bottom-up detail achievable through direct bottom-up integration. However, larger models should be solvable with the aid of decomposition techniques, which allow tight and theoretically consistent linking of a top-down model with bottom-up submodels. This is another focus of our own-going research.

Keywords: $\quad$ Intertemporal general equilibrium, optimal forest management, mixed complementarity 


\section{INTRODUCTION}

Management of forests for timber and other values, deforestation and afforestation are subjects of major policy interest. They have important implications for climate change and food security at regional and global scales. To robustly quantify impacts of policies on forests and on land use generally requires accounting for interactions not only between agricultural and forestry sectors, but also energy and other sectors. At larger scales, these interactions may also involve linkages through international trade. General equilibrium (GE) models are one of the few analytical tools that can represent interactions between all sectors and regions of the global economy, and can be used to assess the direct and indirect (sometimes counter-intuitive) effects of climate and other policies. While significant advances have been made in the representation of land use and land use changes in GE models, important challenges remain. One challenge is to adequately model forestry (Sohngen et al., 2009; Pant, 2010). In this paper, we show how a dynamics of age-structured production forests can be integrated into a top-down intertemporal GE model.

Dynamic models of timber supply are found in partial equilibrium models developed by forest economists. For example, the Global Forest Products Model (GFPM) (Buongiorno et al., 2003) provides a detailed representation of the supply of and international trade in timber and harvested wood products within a recursive dynamic partial equilibrium framework. The Global Timber Model (GTM) (Sedjo and Lyon, 1990; Sohngen et al., 1999) focuses on global timber supply and demand within an optimal dynamic partial equilibrium framework. The GTM is an intertemporal optimisation model in which forestry producers seek to maximise profits subject to various constraints associated with different forest management regimes.

In most GE models that distinguish a forest sector, it is modelled as any other sector. This overlooks the slow dynamic responses that result from the production of outputs using land and other inputs applied over preceding decades. However, recently there have been efforts to model forests and forestry more realistically. Golub et al. (2009) extend a recursive dynamic version of the GTAP-AEZ model to model deforestation, using input and output data of the GTM. Pant (2010) proposes a more comprehensive approach in a recursive dynamic framework, explicitly modelling (as relevant) activities of planting, growth and logging. In this paper we develop and demonstrate a similar bottom-up representation within an intertemporal GE framework. Importantly, this allows us to endogenise intertemporally optimal decision-making in forestry.

\section{THE CliMAT-DGE MODEL}

Our computational framework CliMAT-DGE (Climate Mitigation, Adaptation and Trade in Dynamic General Equilibrium) is ultimately intended to consist of a number of tightly linked economic and biogeophysical models. The central component of this computational framework, which we describe here, is a multiregional intertemporal general equilibrium (GE) model. Each region has a single representative household. We assume households have perfect foresight and maximise the discounted sum of their instantaneous utilities, subject to a lifetime budget constraint. Firms are assumed to be identical within each production sector and to operate with constant returns to scale in perfectly competitive markets. Regions are linked by bilateral trade flows, modelled under the Armington assumption, with imperfect substitution between domestic and imported products from different regions. International transport margins are associated with bilateral trade flows. Taxes and subsidies on output, factor inputs, intermediate and final consumption of goods are modelled, as are taxes and subsidies on bilateral trade flows.

Firms' technologies are described by nested CES, Cobb-Douglas and Leontief production functions. Different nesting structures are used for agricultural and forestry sectors, each of the coal, oil, gas, oil refining and electricity sectors, and manufacturing and service sectors. Sectors use intermediate inputs, capital and labour. Agricultural and forestry sectors use land, while the primary energy sectors use sector-specific and depletable resources. Capital, once installed, is sector specific and depreciates at a constant rate.

Following Mathiesen (1985) and Lau et al. (2002), the model is formulated as a mixed complementarity problem (MCP) in GAMS ${ }^{\mathrm{TM}}$ and solved using the PATH solver (Ferris and Munson, 1998) with a five-year time-step. It is calibrated to the GTAP version 7.1 database (Narayanan and Walmsley, 2008), which we aggregate here to thirteen sectors and four regions: the United States (US), rest of OECD (ROECD), developing oil-producing countries (OIL), and rest of the world (RoW).

\section{FORESTRY DYNAMICS IN GENERAL EQUILIBRIUM}

Forests are managed in many different ways, which may be more or less economically optimal with respect to timber and other values (e.g. carbon storage, recreation, biodiversity). To represent various types of forest and forms of management within a dynamic intertemporal general equilibrium model, we first need to describe them in a way that is sufficiently rich while remaining analytically tractable. Arguably, the GTM provides just such a description; indeed, it is presented in just this light by Sohngen et al (2009). In this paper, we limit our focus to 
planted or naturally regenerating (i.e. self-seeding) production forests comprising equal-aged stands. Such forests dominate production in temperate regions. Our objective is to account for the optimal management of such production forests, including determination of the optimal intensity of planting, management and harvesting and optimal harvest age. In many developing, tropical and sub-tropical countries, a large fraction of timber supply is associated with harvesting or clearance of primary forests. This poses different modelling challenges that we will deal with in future research.

In the GTM, a biomass growth function gives biomass volume as a function of rotation length and management inputs associated with planting and silviculture. The equations are parameterised to reflect the growth and management of different species in different regions. In the GTM, the optimal rotation length is determined endogenously to maximise the present value of current and future rotations. The essential feature of this calculation is that there is a trade-off between the increased yields obtained from longer rotations, and the opportunity cost of delaying harvest of the current and future rotations. Non-timber values, such as forest carbon credits may also be considered.

The problem is slightly different in a general equilibrium setting in which we have competing (agricultural) land uses and an explicit market for land. Recalling our earlier assumptions of competitive markets and constant returns to scale, we wish to choose the input proportions and a harvest age that will yield the maximum of zero pure profits and equalise (discounted) marginal revenues and costs. As in the GTM, our approach is to use complementarity conditions to determine endogenously the particular proportions and rotation length(s) that achieve this.

We define production functions for forestry that combine land and other inputs to produce logs for some harvest age $a$. In these production functions, planting inputs (if relevant) are used in period $t$, together with land in periods $t$ to $t+a-1$ and logging inputs in period $t+a$. Depending on the forest management regime, it may additionally be desired to model silvicultural management inputs (associated with, e.g. thinning) at one or more periods between $t$ and $t+a$, and there may be associated secondary outputs (e.g. thinnings). Non-timber secondary outputs (e.g. forest carbon credits) can also be modelled. The important restriction on this production function is that the land input is the same in all periods, as production of logs in period $t+a$ requires that trees remain on a given area of land up to this time. In Figure 1, we illustrate the structure of a single production function with planting, land and logging inputs.

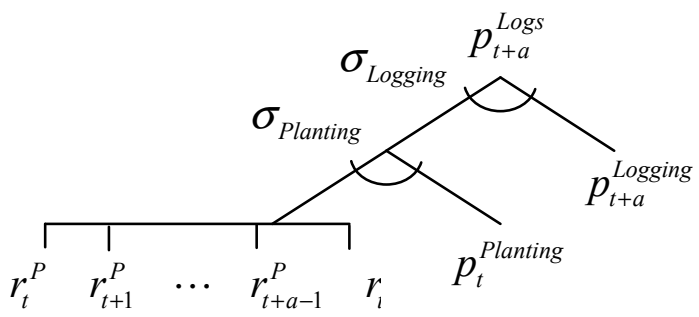

Figure 1. Nested production function for forestry

For each forest type in a given region (or in the simplest case, for a single forest type representative of that region) several such production functions are defined, one for each allowable discrete harvest age $a$ that corresponds to an integer number of time periods. These functions will differ in the number of time periods for which land is required and the proportions of non-land inputs. Output per unit of land as a function of $a$ will reflect a yield curve for marketable output reflective of the forest type and region. Upper and lower bounds on $a$ may reflect only the range required to accommodate likely variations in relative prices and demand, or may also reflect structural factors (e.g. a regulatory minimum harvest age). Complementarity between the negative profits and level of output of production functions for each allowable harvest is exploited to endogenously determine optimal harvest age(s) in any period.

We calibrate forestry production functions assuming that a forest is in dynamic equilibrium, per hectare yields increasing at the same rate as labour productivity. Increasing yields may result from improvements in log quality, as well as quantity. This fits with the common practice of calibrating an intertemporal general equilibrium model under the assumption that the economy is on a balanced growth path with Hicks-neutral technological progress.

Calibration procedures could be devised for more general cases, but we leave this problem

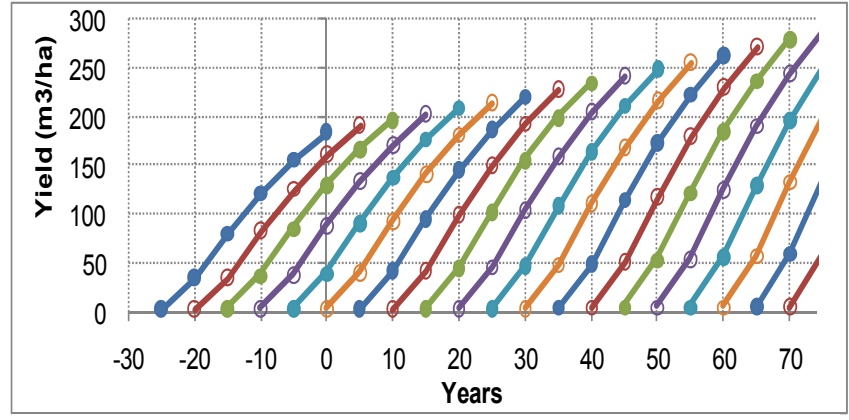

Figure 2. Schematic of increasing yields for successive forest rotations of 6 periods 
for future research. Assuming that the benchmark dataset provides returns to capital, labour and land in the forest sector and we know the initial equilibrium harvest age, the problem is to distinguish the initial value of standing timber from that of the bare forest land. This reflects our belief that for large regions, estimates of the optimal harvest age will generally be more robust than estimates of average stumpage rates (i.e. return to bare forest land).

Due to the increase of yields over time, the initial volume distribution of standing timber follows a curve that results from the projection of the yield curve on the growth curve. That is, there are relatively higher volumes in more recently planted and therefore younger age-classes and relatively lower volumes in less recently planted and therefore older age-classes (Figure 2). Given this distribution, we calibrate a parameter of the yield curve consistent with our choice of initial optimal harvest age $a_{0}$. Since the profit function we are constructing must match input-output data for the forest sector, we have only to determine the revenues at ages $a$ relative to those at $a_{0}$.

We calibrate a yield curve consistent with economic optimality of the specified initial harvest age. Assuming for simplicity that the only costs are the annual land rent with undiscounted cost $R$ and harvest costs with undiscounted cost $H$ (independent of $a$ ), and a constant discount rate $r$, the profit function is:

$$
\Pi(a)=Y \exp \left(\frac{B}{a_{0}}-\frac{B}{a}\right)-H-R \sum_{\alpha=1}^{a}(1+r)^{\alpha}
$$

To find the yield/revenue curve parameter $B$, we replace the finite geometric series with the equivalent closed expression, derive the first order conditions with respect to $a$, evaluating for $a=a_{0}$. Solving for $B$ :

$$
B=\frac{R a_{0}^{2}}{r Y}(1+r)^{a_{0}+1} \ln (1+r)
$$

Having calibrated the model in this way, only the production functions for $a=a_{0}$ will have a positive level of output on the initial balanced growth path. The unit profit functions corresponding to production functions for other harvest ages will be negative, and by complementarity, their output will be zero. However, changes in relative prices may result in production functions for different harvest ages becoming active. For example, increasing competition for land resulting in higher land rents will tend to favour shorter rotations. Multiple ages of trees may be harvested in a single period, particularly during the transition to the new steady state growth path. Changes in harvest age may differ in the short, medium and long term. For example, incentivising carbon storage in planted forests may result in a decrease in timber output over the medium term, but a rise in the long term (Sohngen et al., 2009).

Terminal conditions are required to ensure that demand for land is maintained at an appropriate level in the latter part of the simulation. Otherwise, there will be no demand for land to grow trees that will not be harvested during or before the terminal period. For these final periods, the number of which equals the maximum harvest age, we impose constraints requiring that total demand for forest land grows at the same rate as the level of aggregate consumption. These conditions are analogous to the condition for terminal investment demand of Lau et al. (2002). The variable associated with each constraint scales the representative agent's negative endowment of forest land in those periods. Initial conditions for these demands can be set by extrapolating and summing the demands for land for each post-terminal harvest.

For the purposes of this paper, for the US and ROECD regions, we model a single forest type with an initial harvest age of sixty years. As we have not yet implemented an explicit representation of deforestation, we model forestry in the developing OIL and RoW regions like agriculture; using land to produce logs within a single period. This permits immediate conversion of forest to agricultural land in those regions.

\section{AN ILLUSTRATIVE SCENARIO}

To illustrate the model described above, we simulate the capping of emissions in the US and ROECD $40 \%$ below their (increasing) baseline levels. To achieve these reductions, we simulate an internationally linked emissions trading scheme covering $\mathrm{CO}_{2}$ emissions in the US and ROECD. For the US, we also simulate the implementation of a system of credits for storage of carbon in domestically produced harvested wood products (HWP - lumber, paper, etc.). Credits for HWPs are included in the emissions budgets of both regions. Since the primary purpose of this paper is to demonstrate our modelling approach, we do not attempt to develop a realistic baseline but impose the above measures directly on the balanced growth path to which the model is calibrated. Equally, the simulated measures are designed to yield easily interpretable results, rather than to represent realistic policies, which would for example, involve deeper cuts to emissions over time. Finally, we have not 
included any feedback of climate change on the economy. Thus we model only the economic costs of reducing emissions, without accounting for the benefits of limiting climate change.

Impacts in ROECD are more than double those in the US. The greatest impact though is in OIL. Impacts in RoW are modest, but still slightly greater than those in the US.

Table 1 shows the short- and long-run carbon prices and impacts of carbon pricing on macroeconomic variables for the four regions. The differences between sort- and long-run macroeconomic impacts relate primarily to the time required for sector-specific capital stocks to adjust to their new equilibrium levels. This inertia also results in a higher carbon price in the short run (US\$130/t CO $C_{2}$ ) than in the long run (US\$110/t $\left.\mathrm{CO}_{2}\right)$. The US benefits from selling a significant proportion of its emissions allocation to ROECD, which has higher mitigation costs. Output and consumption in all region are higher in the short than in the long run, while the reverse is generally true for investment (RoW being an exception). Negative impacts on the OIL and RoW regions are due to decreased terms of trade, and especially reduced demand for oil and other fossil fuels.

Table 1. Short and long-run carbon prices and impacts of carbon pricing by region in the ETS scenario

\begin{tabular}{|l|r|r|r|r|r|r|r|r|}
\hline & \multicolumn{4}{|c|}{ Short run (first five year period) } & \multicolumn{3}{c|}{ Long run } \\
\hline & \multicolumn{1}{|c|}{ USA } & \multicolumn{1}{c|}{ ROECD } & \multicolumn{1}{c|}{ OIL } & \multicolumn{1}{c|}{ RoW } & \multicolumn{1}{c|}{ USA } & ROECD & \multicolumn{1}{c|}{ OIL } & \multicolumn{1}{c|}{ RoW } \\
\hline Carbon price US\$/t CO $\mathrm{CO}_{2}$ & 130 & 130 & 0 & 0 & 110 & 110 & 0 & 0 \\
\hline GDP & 0.67 & -0.11 & -4.5 & 0.31 & -0.62 & -1.92 & -7.7 & -1.10 \\
\hline Consumption & 0.33 & -0.47 & -4.5 & 0.37 & -0.94 & -2.30 & -7.7 & -1.08 \\
\hline Investment & -5.18 & -4.86 & -8.3 & 1.73 & -4.13 & -3.66 & -6.2 & -0.46 \\
\hline Capital & 0.00 & 0.00 & 0.0 & 0.00 & -4.13 & -3.66 & -6.2 & -0.46 \\
\hline
\end{tabular}

While the US HWP measure results in a carbon price only $0.8 \%$ lower than would otherwise be the case, , it yields a dramatic increase in forest output (Figure 3) and area (Figure 4) in the US. Forest area, which is $4.0 \%$ of quality-weighted productive land in the baseline, rises to $5.7 \%$ in the short term and output increases $30 \%$.

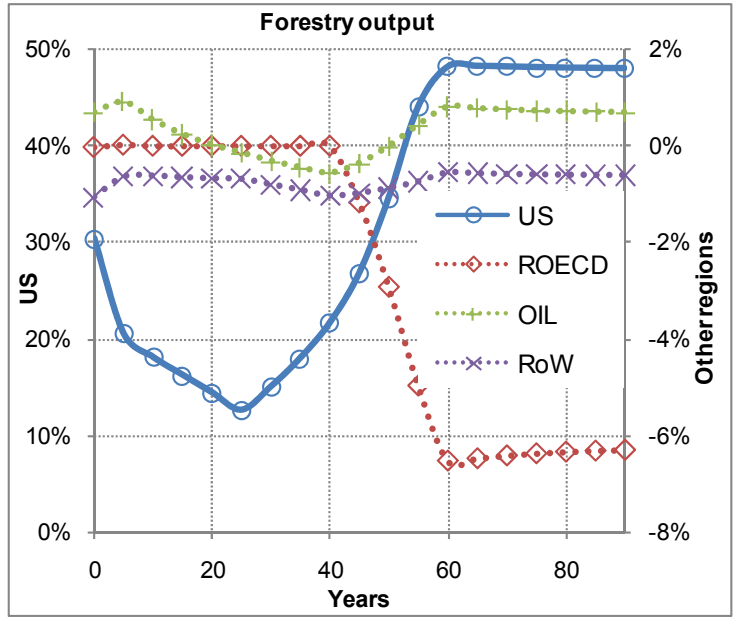

Figure 3. Change of forest sector output relative to baseline (US left, other regions right axis)

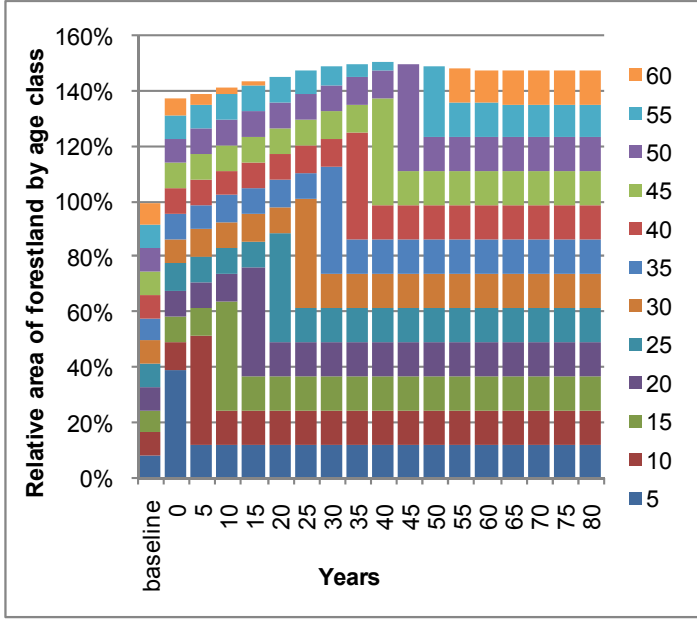

Figure 4. US forest area by age class relative to baseline

Increased harvests in the US must at first come from the initial forest inventory. However, carbon credits make it profitable to harvest younger trees: the harvest age falls 60 to 50 years by year 50, at which time trees planted in the first period begin to be harvested. Over the next two periods, the harvest age rises back to 60 years. In the long term, forest output increases by $49 \%$. The increased output results almost entirely from increases in forest land, rather than increased management intensity, because there are only slight changes in the relative prices of land versus logging services. In ROECD, there is a decline in forest output from the period beginning in year 45 , with an eventual decline of over $6 \%$ by year 60 . These impacts are despite the substantial neutralizing effect of the border carbon adjustment for US log exports. In RoW, forest output declines slightly, fluctuating between 1.1 and in the long run, $-0.6 \%$. In the long run, forest output increases $0.7 \%$ in the OIL, due a relatively greater decrease in demand for agricultural land. However, this region accounted for only $4 \%$ of global forest sector output in the benchmark year.

Impacts of carbon pricing on other sectors of the economy are shown in Table 2. There are large reductions of output of primary energy sectors in the two developed regions and to a lesser extent, in the two developing regions. In the oil refining, electricity and energy-intensive manufacturing and transport sectors, there are also substantial reductions of output in the two developed regions, but increases in output in the two developing 
regions. There are modest negative impacts on output of the crop and agricultural, food products, HWP, and non-energy-intensive manufacturing sectors in the developed regions, and generally smaller positive impacts on the same sectors in the two developing regions. In general, all of the long-run impacts are slight more negative or less positive in the long run than in the short run. However, there are positive long-run impacts for some moderately energy-intensive sectors in the two developing regions.

Table 2. Changes in sectoral output relative to baseline (\%) in the short and long run

\begin{tabular}{|c|c|c|c|c|c|c|c|c|}
\hline & \multicolumn{4}{|c|}{ Short run } & \multicolumn{4}{|c|}{ Long run } \\
\hline & USA & ROECD & OIL & RoW & USA & ROECD & OIL & RoW \\
\hline Cropping & -4 & -1.8 & 1.7 & 0.4 & -6 & -3.0 & -0.7 & -0.2 \\
\hline Agriculture & -2 & -1.7 & 0.3 & 0.2 & -3 & -3.3 & -2.4 & -0.4 \\
\hline Forestry & 30.4 & 0.0 & 0.7 & -1.1 & 48.0 & -6.3 & 0.7 & -0.6 \\
\hline Coal & -44 & -26.0 & -5.8 & -7.5 & -45 & -31.2 & -5.6 & -6.3 \\
\hline Gas & -33 & -20.0 & -7.3 & -10.8 & -37 & -39.5 & -9.6 & -8.4 \\
\hline Oil & -14 & -6.4 & -4.9 & -9.6 & -22 & -18.3 & -9.3 & -7.5 \\
\hline Oil refining & -29 & -14.6 & 12.5 & 6.7 & -30 & -18.6 & 4.6 & 2.9 \\
\hline Electricity & -24 & -14.7 & 4.6 & 3.3 & -24 & -15.0 & -1.4 & 1.8 \\
\hline Food products & -2 & -1.2 & 0.4 & 0.1 & -3 & -2.8 & -2.9 & -0.7 \\
\hline HWPs & -3 & -1.6 & 3.3 & 0.5 & -3 & -3.2 & 3.4 & 0.2 \\
\hline Energy-intensive \& transport & -13 & -5.0 & 8.9 & 4.3 & -15 & -7.1 & 8.1 & 4.3 \\
\hline Non-energy-intensive & -3 & -1.6 & 2.5 & -0.2 & -4 & -2.8 & 2.5 & -0.4 \\
\hline Services & 0.3 & -0.2 & -0.9 & -0.1 & -0.4 & -1.5 & -4.5 & -0.8 \\
\hline
\end{tabular}

To isolate flow-on impacts of the US HWP credit policy we show in Table 3 the marginal changes in sectoral output compared to a simulation in which there are no credits. The most direct effect is on the HWP sector. However, HWP output rises much less than might be expected: $0.75 \%$ in the short run and $1.4 \%$ in the long run. Several factors explain these small impacts. Firstly, despite the export border adjustment, there are rises in US $\log$ exports and falls in imports: in the long run, exports rise by $2.1 \%$ while imports fall by $0.9 \%$. Secondly, the GTAP database shows a third of US forest sector output being consumed by other sectors. Thirdly, much lower $\log$ prices ( $-37 \%$ in the long run) and much higher prices of energy (most notably electricity rises $70 \%$ in the long run) motivate significant input substitution within the HWP sector. This could be interpreted as a shift toward less energy-intensive but lower value products.

Table 3. Marginal impacts of US HWP credits on percentage changes in sectoral output

\begin{tabular}{|c|c|c|c|c|c|c|c|c|}
\hline & \multicolumn{4}{|c|}{ Short run } & \multicolumn{4}{|c|}{ Long run } \\
\hline & USA & ROECD & OIL & RoW & USA & ROECD & OIL & RoW \\
\hline Cropping & -0.57 & 0.07 & 0.02 & 0.07 & -0.82 & 0.18 & -0.01 & 0.05 \\
\hline Forestry & 30 & -0.02 & -0.39 & -0.83 & 49 & -5.8 & 0.97 & -0.27 \\
\hline Coal & 0.12 & 0.10 & -0.02 & 0.01 & 0.14 & 0.12 & 0.00 & 0.01 \\
\hline Gas & 0.15 & 0.14 & 0.02 & 0.03 & 0.12 & 0.19 & 0.03 & 0.02 \\
\hline Oil refining & 0.15 & 0.10 & -0.06 & -0.03 & 0.14 & 0.12 & -0.02 & -0.01 \\
\hline Electricity & 0.12 & 0.08 & -0.02 & -0.02 & 0.15 & 0.08 & 0.01 & -0.01 \\
\hline Food products & -0.04 & 0.01 & 0.00 & 0.01 & -0.04 & 0.04 & 0.00 & 0.01 \\
\hline HWPs & 0.75 & 0.11 & -0.09 & -0.16 & 1.4 & -0.11 & -0.19 & -0.28 \\
\hline Energy-intensive \& transport & 0.05 & 0.04 & -0.05 & -0.02 & 0.06 & 0.07 & -0.04 & -0.02 \\
\hline
\end{tabular}

The largest percentage changes in land use occur in the US. These are shown in Table 4, where we see that the predominant effect is movement of land from cropping into forestry; in the long run, $2.1 \%$ of land by value. This accommodates the wave of planting observed in Figure 4. In the absence of HWP credits, this shift would not have occurred, but a smaller proportion of land would have shifted from cropping to animal agriculture. In other regions, changes are smaller and in opposing directions. 
Table 4. Land use shares and policy-induced changes in the US (\% of quality-weighted area)

\begin{tabular}{|l|r|r|r|r|r|}
\hline & \multicolumn{1}{|c|}{ Baseline land use shares } & \multicolumn{2}{|c|}{ Changes in land use shares } & \multicolumn{2}{c|}{ Marginal impacts of HWP credits } \\
\hline & & \multicolumn{2}{|c|}{ Short run } & \multicolumn{1}{c|}{ Long run } & \multicolumn{2}{c|}{ Short run } & \multicolumn{1}{c|}{ Long run } \\
\hline Cropping & 78.9 & -1.73 & -2.05 & -1.45 & -1.69 \\
\hline Animal agriculture & 17.0 & 0.03 & 0.04 & -0.26 & -0.28 \\
\hline Forestry & 4.0 & 1.70 & 2.01 & 1.70 & 1.98 \\
\hline
\end{tabular}

\section{CONCLUSIONS AND FUTURE DIRECTIONS}

We have developed and demonstrated the integration of bottom-up representations of planted or naturally regenerating production forests within a top-down intertemporal GE framework. Using multiperiod production functions and complementarity conditions, we can account for the optimal intensity of planting, management and harvesting and the optimal harvest age for age-structured forests. A comparable bottom-up treatment of timber production from and clearance of primary forests is the subject of ongoing research. These dynamic representations of forestry will allow for more robust assessments of policies such as domestic greenhouse gas emissions trading schemes or Reducing Emissions from Degradation and Deforestation (REDD) Plus in developed and developing countries. It is also planned to extend the model to account for climate change impacts on primary productivity in both forestry and agriculture.

An illustrative scenario using a four-region version of our CliMAT-DGE model with bottom-up forestry showed the economic impacts of carbon credits for HWPs in the US within a wider context of pricing $\mathrm{CO}_{2}$ emissions in developed countries. We showed not only a significant expansion of forestland and output in the US, but changes in age composition of the forest estate and harvest ages during a six decade transition. Marginal flowon effects of the US HWP credits were small, but larger effects could be expected for policies affecting a larger share of global forest production, or in regions where forestry is economically more important.

Computational considerations limit the number of regions and the level of bottom-up detail achievable through direct bottom-up integration. However, larger models should be solvable with the aid of decomposition techniques, which allow tight and theoretically consistent linking of a top-down model with bottom-up submodels. This is another focus of our own-going research.

\section{ACKNOWLEDGEMENTS}

This work is part of a project funded by the Ministry for Agriculture and Forestry, New Zealand. Any opinions, findings, and conclusions or recommendations expressed in this material are those of the authors and do not necessarily reflect the views of the Ministry for Agriculture and Forestry.

\section{REFERENCES}

Buongiorno, J., Zhu, S., Zhang, D., Turner, J.A. and Tomberlin, D. (2003). The global forest products model: structure, estimation and applications, Academic Press, San Diego, CA.

Ferris, M. C. and Munson, T. S. (1998). PATH 4.6 user manual. University of Wisconsin, Madison, WI.

Golub, A., Hertel, T. W. and Sohngen, B. (2009). In Economic analysis of land use in global climate change policy, Eds, Hertel, T.W., Rose, S. and Tol, R.S.J., Routledge, London, UK.

Lau, M. I., Pahlke, A. and Rutherford, T. F. (2002). Approximating infinite-horizon models in a complementarity format: a primer in dynamic general equilibrium analysis. Journal of Economic Dynamics and Control, 26, 577-609.

Mathiesen, L. (1985) Computation of economic equilibria by a sequence of linear complementarity problems. Mathematical Programming Study, 23, 144-162.

Narayanan, B. G. and Walmsley, T. L. (Eds.) (2008). Global trade, assistance, and production: The GTAP 7 data base, Center for Global Trade Analysis, Purdue University, Lafayette, IN.

Pant, H.M. (2010). An analytical framework for incorporating land use change and forestry in a dynamic CGE model. Paper presented at AARES 54th Annual Conference, Adelaide, Australia, February 10-12.

Sedjo, R.A. and Lyon, K.S. (1990). The long-term adequacy of world timber supply. Resources for the Future, Washington, DC.

Sohngen, B., Golub, A. and Hertel, T.W. (2009). In Economic analysis of land use in global climate change policy, Eds, Hertel, T.W., Rose, S. and Tol, R.S.J., Routledge, London, UK.

Sohngen, B., Mendelsohn, R. and Sedjo, R. (1999). Forest management, conservation, and global timber markets. American Journal of Agricultural Economics, 81, 1-13. 